\title{
Sleep apnea and inflammation - getting a good night's sleep with omega-3 supplementation
}

\author{
Fulvio A. Scorza ${ }^{1}$, Esper A. Cavalheiro ${ }^{1}$, Carla A. Scorza ${ }^{1}$, José C. F. Galduróz ${ }^{2}$, Sergio Tufik ${ }^{2}$ and \\ Monica L. Andersen ${ }^{2} *$
}

${ }^{1}$ Disciplina de Neurologia Experimental, Universidade Federal de São Paulo/Escola Paulista de Medicina (UNIFESP/EPM), São Paulo, Brazil

${ }^{2}$ Departamento de Psicobiologia, Universidade Federal de São Paulo/Escola Paulista de Medicina (UNIFESP/EPM), São Paulo, Brazil

\section{Edited by:}

David Gozal, University of Chicago,

USA

\section{Reviewed by:}

Sina A. Gharib, University of

Washington, USA

Irma Rukhadze, Harvard University, USA

${ }^{*}$ Correspondence:

Monica L. Andersen, Departamento de Psicobiologia, Universidade

Federal de São Paulo/Escola Paulista de Medicina (UNIFESP/EPM), Rua

Napoleão de Barros, 925, São Paulo 04024-002, Brazil

e-mail:mandersen@unifesp.br.

ml.andersen12@gmail.com
Obstructive sleep apnea (OSA) is a multifactorial sleep disorder associated with an increased risk of cardiovascular mortality and morbidity. Several mechanisms have been proposed to explain the association between OSA and cardiovascular dysfunction. One of the proposed mechanisms is an inflammatory response to OSA mediated by tumor necrosis factor (TNF- $\alpha$ ). Patients with OSA have higher plasma, serum, and intracellular levels of TNF- $\alpha$, which may be reduced after apnea treatment with continuous positive airway pressure (CPAP). Because TNF- $\alpha$ plays an important role in OSA related cardiovascular morbidity, the present review aims to identify other preventive measures, in addition to CPAP, that may minimize the inflammatory process in OSA and consequently the risk of premature death due to cardiovascular dysfunction. Thus, we hypothesized that a nutritional immunology profile, i.e., supplementation with omega-3 fatty acids, may be valuable for individuals with OSA.

Keywords: obstructive sleep apnea, omega-3, cardiovascular, inflammation, TNF- $\alpha$
Obstructive sleep apnea (OSA), a common form of sleepdisordered breathing, is a multifactorial sleep disorder associated with several risk factors, including excess body weight, male gender, older age, neck circumference, body mass index, and high blood pressure $(1,2)$. OSA affects up to $32.8 \%$ of the population (3) and, as demonstrated in the Sleep Heart Health study, is linked to an increased risk of cardiovascular mortality and morbidity (4). Population-based longitudinal studies have shown that individuals with severe OSA have a threefold greater risk of allcause mortality and a higher cardiovascular mortality at 18-year follow-up (5-7). In addition, OSA has been independently associated with specific cardiovascular outcomes such as hypertension $(8)$, stroke $(9,10)$, myocardial ischemia $(11,12)$, and arrhythmias with an increased risk for sudden cardiac death $(13,14)$. Several mechanisms have been proposed to explain the association between OSA and cardiovascular dysfunction (15). Interestingly, the accumulated evidence based on clinical studies as well as animal models and cell culture indicates that inflammatory cytokines, especially tumor necrosis factor (TNF, also known as TNF- $\alpha$ ), play an important role in OSA related cardiovascular morbidity (15). In 1975, TNF- $\alpha$ was identified as an endotoxin induced glycoprotein that caused hemorrhagic necrosis of sarcomas that had been transplanted into mice. Human TNF was cloned 10 years later (16-18). Briefly, TNF- $\alpha$ is an inflammatory cytokine produced by macrophages/monocytes during acute inflammation and is responsible for a diverse range of signaling events within cells that lead to necrosis or apoptosis (19). In addition to its involvement in a diverse range of inflammatory, infectious, and malignant conditions, the importance of TNF- $\alpha$ has been highlighted by the efficacy of anti-TNF antibodies or soluble TNF receptors (TNFRs) in controlling inflammatory conditions (18). Several important discoveries have been made in elucidating the precise role of TNF$\alpha$ in the cardiovascular pathogenesis of OSA. Entzian et al. (20) demonstrated that the circadian rhythm of TNF- $\alpha$ release was significantly disturbed in OSA patients, suggesting that TNF- $\alpha$ could play a pathophysiologic role in OSA. After this discovery, TNF- $\alpha$ levels were extensively studied in individuals with OSA (15). In most of these studies, TNF- $\alpha$ was measured in plasma or serum; however, in several studies cell-specific levels were also evaluated $(15,21,22)$. In 2003, Dyugovskaya et al. (21) characterized the cytokine profile of gammadelta $\mathrm{T}$ cells in patients with OSA and control subjects. The major finding regarding OSA gammadelta $\mathrm{T}$ cells was a significant increase in the intracellular content of proinflammatory cytokines TNF- $\alpha$ in OSA individuals when compared with the control group. A year later, it was shown that individuals with moderate-to-severe OSA had spontaneous production of TNF- $\alpha$ by monocytes and elevated serum levels of TNF- $\alpha$ (23). Ryan et al. demonstrated an important association between TNF- $\alpha$ and OSA severity, as serum levels of TNF- $\alpha$ was higher in subjects with OSA than in subjects without OSA (24). Moreover, other authors have also demonstrated that continuous positive airway pressure (CPAP) therapy decreased the TNF- $\alpha$ level in OSA patients (25). Following this line of reasoning, Dorkova et al. (26) determined the effects of 8 weeks of CPAP therapy on inflammation in patients with severe OSA. They provide additional evidence that OSA caused an increase in TNF- $\alpha$ and also concluded that compliance with a CPAP regimen can improve the expression of this inflammatory cytokine. Furthermore, evaluating obese Asian Indians with OSA, Bhushan et al. (27) clearly demonstrated that the frequency of the TNF- $\alpha(-308 \mathrm{~A})$ allele and the serum TNF- $\alpha$ 
level was significantly higher in OSA (27). Despite this evidence the role of TNF in OSA there is still controversy in the scientific literature on this aspect. One possible explanation pair these divergences could be related to disease duration, intensity, patient age, among other factors.

Based on these findings and the fact that TNF- $\alpha$ plays an important role in OSA related cardiovascular morbidity, we aimed to identify other preventive measures, aside from CPAP (successful treatment with CPAP appears to at least partially abrogate this risk) (28), that can minimize the inflammatory process in patients with OSA and thereby prevent possible cardiovascular dysfunction that may increase the risk of premature death. A possible alternative therapy is nutritional immunology, i.e., supplementation with omega-3 fatty acids (omega-3 FAs). For this proposal, several lines of evidence should be explored. First, the beneficial effects of omega-3 FAs in the cardiovascular system have been described since the late 1970s. It was demonstrated that the low prevalence of cardiac diseases in Eskimos might be due to their high dietary intake of omega-3 FAs (29). Currently, several studies have clearly demonstrated that omega-3 FAs can help prevent coronary heart disease, reduce arrhythmias and thrombosis, lower plasma triglyceride levels, and reduce blood clotting tendency (30). However, there is still controversy regarding the real cardiovascular benefits of omega-3 FAs. According to Barrett (31), the majority of epidemiological studies and interventions demonstrate favorable cardiovascular outcomes with omega-3 FAs; however, Galli and Brenna (32) have recently criticized the methodological metaanalysis and concluded that omega-3 FAs were not effective in preventing cardiac disorders.

Second, the relationship between omega-3 FAs and OSA is still rarely evaluated and described in the literature. One of the most relevant studies on this topic was conducted by Ladesich et al. (33). In this study, the authors investigated the relationship between omega-3 fatty acid docosahexaenoic acid (DHA) levels in red blood cells (RBC) and OSA severity in 350 sequential patients undergoing sleep studies. The authors defined the severity categories as none/mild, moderate, and severe based on apnea hypopnea index scores of $0-14,15-34$, and $>34$, respectively (33). Briefly, they demonstrated that RBC DHA was inversely related to OSA severity and that for each 1-SD increase in DHA levels, a patient was approximately 50\% less likely to be classified with severe OSA (33). Thus, the authors concluded that disordered membrane fatty acid patterns may play a causal role in OSA and that the assessment of RBC DHA levels might help in the diagnosis of OSA (33). We fully agree with the authors' conclusions, and our research group recently postulated that scientists and clinicians should work together in a worldwide network focused on basic scientific research programs and clinical studies to accurately establish the use of omega-3 FAs for at risk individuals to prevent sudden death in OSA patients (34).

Third, it is well documented that chronic inflammation is a characteristic of severe chronic heart failure (CHF), and inflammatory cytokines have been shown to reduce left ventricular (LV) function, promote LV remodeling, and deteriorate endothelial function (35-37). Thus, as recent published studies have accurately demonstrated, supplementation with omega-3 FAs improves systolic LV function and endothelial function as well as decreases markers of inflammation in CHF of non-ischemic origin (37) and other clinical conditions $(38,39)$. Therefore, it is entirely reasonable to postulate that omega-3 FA supplementation will be useful in minimizing the inflammatory cascade and therefore improving cardiac function in individuals with OSA.

In addition to the above points, omega- 3 FAs are well tolerated with minimal adverse effects (40). As noted, the human body cannot synthesize omega-3 FAs; therefore, it must be ingested from the diet. According to the vast literature, seafood (commonly found in fish and fish oil) is the only food that provides large amounts of omega-3 FAs $(30,41)$. The best seafood choices are wild salmon, anchovies, sardines, trout, herring, and tuna $(30,41)$. Due to the importance of the consumption of fish rich in omega-3 FAs, international guidelines have suggested that the general population should consume at least $250 \mathrm{mg}$ /day of long-chain omega-3 FAs or at least two servings/week of oily fish (42). For individuals who want a contaminant-free diet but would like to enjoy the benefits of omega-3 FAs, fish oil supplements, or foods such as walnuts or oils (flax, canola, and soybean) can be consumed $(43,44)$.

Overall, it is clear that inflammation (especially increased levels of TNF- $\alpha$ ) plays an important role in OSA related cardiovascular morbidity (45). Due to the beneficial actions of omega-3 FAs for the cardiovascular system and in minimizing the inflammatory process, our research group has hypothesized that omega-3 FA supplementation may be able to reduce cardiac dysfunction and even the occurrence of premature death in patients with OSA.

We believe that new experimental, epidemiological, and clinical studies should be evaluated to establish the relationship between OSA, inflammation, and omega-3 FAs. In the meantime, we should be optimistic and remember these words by the American writer and philosopher Robert M. Pirsig: For every fact there is infinity of hypotheses.

\section{AUTHOR CONTRIBUTIONS}

All authors were involved in writing the paper and had final approval of the submitted and published versions.

\section{ACKNOWLEDGMENTS}

This article has been supported by grants from FAPESP (Fundação de Amparo à Pesquisa do Estado de São Paulo); CNPq (Conselho Nacional de Desenvolvimento Científico e Tecnológico); FAPESP/FAPEMIG; FAPESP/PRONEX and FAPESP/CNPq/MCT (Instituto Nacional de Neurociência Translacional); and AFIP.

\section{REFERENCES}

1. Young T, Shahar E, Nieto FJ, Redline S, Newman AB, Gottlieb DJ, et al. Predictors of sleep-disordered breathing in community-dwelling adults: the Sleep Heart Health Study. Arch Intern Med (2002) 162:893-900. doi:10.1001/archinte. 162.8 .893

2. Mirrakhimov AE, Sooronbaev T, Mirrakhimov EM. Prevalence of obstructive sleep apnea in Asian adults: a systematic review of the literature. BMC Pulm Med (2013) 13:10. doi:10.1186/1471-2466-13-10

3. Tufik S, Santos-Silva R, Taddei JA, Bittencourt LR. Obstructive sleep apnea syndrome in the Sao Paulo Epidemiologic Sleep Study. Sleep Med (2010) 11:441-6. doi:10.1016/j.sleep.2009.10.005

4. Gottlieb DJ, Yenokyan G, Newman AB, O'Connor GT, Punjabi NM, Quan SF, et al. Prospective study of obstructive sleep apnea and incident coronary heart disease and heart failure: the sleep heart health study. Circulation (2010) 122:352-60. doi:10.1161/CIRCULATIONAHA.109.901801 
5. Marshall NS, Wong KK, Liu PY, Cullen SR, Knuiman MW, Grunstein RR. Sleep apnea as an independent risk factor for all-cause mortality: the Busselton Health Study. Sleep (2008) 31:1079-85.

6. Young T, Finn L, Peppard PE, Szklo-Coxe M, Austin D, Nieto FJ, et al. Sleep disordered breathing and mortality: eighteen-year follow-up of the Wisconsin sleep cohort. Sleep (2008) 31:1071-8.

7. Selim B, Won C, Yaggi HK. Cardiovascular consequences of sleep apnea. Clin Chest Med (2010) 31:203-20. doi:10.1016/j.ccm.2010.02.010

8. Peppard PE, Young T, Palta M, Skatrud J. Prospective study of the association between sleep-disordered breathing and hypertension. N Engl J Med (2000) 342:1378-84. doi:10.1056/NEJM200005113421901

9. Arzt M, Young T, Finn L, Skatrud JB, Bradley TD. Association of sleep-disordered breathing and the occurrence of stroke. Am J Respir Crit Care Med (2005) 172:1447-51. doi:10.1164/rccm.200505-702OC

10. Munoz R, Duran-Cantolla J, Martínez-Vila E, Gallego J, Rubio R, Aizpuru F, et al. Severe sleep apnea and risk of ischemic stroke in the elderly. Stroke (2006) 37:2317-21. doi:10.1161/01.STR.0000236560.15735.0f

11. Mooe T, Rabben T, Wiklund U, Franklin KA, Eriksson P. Sleep-disordered breathing in women: occurrence and association with coronary artery disease. Am J Med (1996) 101:251-6. doi:10.1016/S0002-9343(96)00122-2

12. Peled N, Abinader EG, Pillar G, Sharif D, Lavie P. Nocturnal ischemic events in patients with obstructive sleep apnea syndrome and ischemic heart disease: effects of continuous positive air pressure treatment. J Am Coll Cardiol (1999) 34:1744-9. doi:10.1016/S0735-1097(99)00407-6

13. Mehra R, Benjamin EJ, Shahar E, Gottlieb DJ, Nawabit R, Kirchner HL, et al. Association of nocturnal arrhythmias with sleep-disordered breathing: the Sleep Heart Health Study. Am J Respir Crit Care Med (2006) 173:910-6. doi:10.1164/rccm.200509-1442OC

14. Gami AS, Howard DE, Olson EJ, Somers VK. Day-night pattern of sudden death in obstructive sleep apnea. N Engl J Med (2005) 352:1206-14. doi:10.1056/NEJMoa041832

15. Lavie L, Polotsky V. Cardiovascular aspects in obstructive sleep apnea syndrome - molecular issues, hypoxia and cytokine profiles. Respiration (2009) 78:361-70. doi:10.1159/000243552

16. Carswell EA, Old LJ, Kassel RL, Green S, Fiore N, Williamson B. An endotoxininduced serum factor that causes necrosis of tumors. Proc Natl Acad Sci U S A (1975) 72:3666-70. doi:10.1073/pnas.72.9.3666

17. Pennica D, Hayflick JS, Bringman TS, Palladino MA, Goeddel DV. Cloning and expression in Escherichia coli of the cDNA for murine tumor necrosis factor. Proc Natl Acad Sci U S A (1985) 82:6060-4. doi:10.1073/pnas.82.18.6060

18. Bradley JR. TNF-mediated inflammatory disease. J Pathol (2008) 214:149-60. doi:10.1002/path.2287

19. Idriss HT, Naismith JH. TNF alpha and the TNF receptor superfamily: structurefunction relationship(s). Microsc Res Tech (2000) 50:184-95. doi:10.1002/10970029(20000801)50:3<184::AID-JEMT2>3.0.CO;2-H

20. Entzian P, Linnemann K, Schlaak M, Zabel P. Obstructive sleep apnea syndrome and circadian rhythms of hormones and cytokines. Am J Respir Crit Care Med (1996) 153:1080-6. doi:10.1164/ajrccm.153.3.8630548

21. Dyugovskaya L, Lavie P, Lavie L. Phenotypic and functional characterization of blood T cells in sleep apnea. Am J Respir Crit Care Med (2003) 168:242-9. doi:10.1164/rccm.200210-1226OC

22. Dyugovskaya L, Lavie P, Lavie L. Lymphocyte activation as a possible measure of atherosclerotic risk in patients with sleep apnea. Ann N Y Acad Sci (2005) 1051:340-50. doi:10.1196/annals.1361.076

23. Minoguchi K, Tazaki T, Yokoe T, Minoguchi H, Watanabe Y, Yamamoto M, et al. Elevated production of tumor necrosis factor-alpha by monocytes in patients with obstructive sleep apnea syndrome. Chest (2004) 126:1473-9. doi:10.1378/chest.126.5.1473

24. Ryan S, Taylor CT, McNicholas WT. Predictors of elevated nuclear factorkappaB-dependent genes in obstructive sleep apnea syndrome. Am J Respir Crit Care Med (2006) 174:824-30. doi:10.1164/rccm.200601-066OC

25. Baessler A, Nadeem R, Harvey M, Madbouly E, Younus A, Sajid H, et al. Treatment for sleep apnea by continuous positive airway pressure improves levels of inflammatory markers - a meta-analysis. J Inflamm (Lond) (2013) 10:13. doi:10.1186/1476-9255-10-13

26. Dorkova Z, Petrasova D, Molcanyiova A, Popovnakova M, Tkacova R. Effects of continuous positive airway pressure on cardiovascular risk profile in patients with severe obstructive sleep apnea and metabolic syndrome. Chest (2008) 134:686-92. doi:10.1378/chest.08-0556
27. Bhushan B, Guleria R, Misra A, Luthra K, Vikram NK. TNF-alpha gene polymorphism and TNF-alpha levels in obese Asian Indians with obstructive sleep apnea. Respir Med (2009) 103:386-92. doi:10.1016/j.rmed.2008.10.001

28. Kent BD, Ryan S, McNicholas WT. Obstructive sleep apnea and inflammation: relationship to cardiovascular co-morbidity. Respir Physiol Neurobiol (2011) 178:475-81. doi:10.1016/j.resp.2011.03.015

29. Dyerberg J, Bang HO. Haemostatic function and platelet polyunsaturated fatty acids in Eskimos. Lancet (1979) 2:433-5. doi:10.1016/S0140-6736(79)91490-9

30. Smith KM, Sahyoun NR. Fish consumption: recommendations versus advisories, can they be reconciled? Nutr Rev (2005) 63:39-46. doi:10.1111/j.17534887.2005.tb00120.x

31. Barrett SJ. The role of omega-3 polyunsaturated fatty acids cardiovascular health. Altern Ther Health Med (2013) 19(Suppl 1):26-30.

32. Galli C, Brenna JT. Omega-3 fatty acid supplementation and cardiovascular disease events. JAMA (2013) 309(1):27. doi:10.1001/jama.2012.116657

33. Ladesich JB, Pottala JV, Romaker A, Harris WS. Membrane level of omega3 docosahexaenoic acid is associated with severity of obstructive sleep apnea. J Clin Sleep Med (2011) 7:391-6. doi:10.5664/JCSM.1198

34. Scorza FA, Cavalheiro EA, Scorza FA, Galduróz JC, Tufik S, Andersen ML. Omega-3 intake in people with obstructive sleep apnea: beauty sleep for the heart. Epilepsy Behav (2013) 29(2):424-6. doi:10.1016/j.yebeh.2013.07. 029

35. Ferrari R, Bachetti T, Confortini R, Opasich C, Febo O, Corti A, et al. Tumor necrosis factor soluble receptors in patients with various degrees of congestive heart failure. Circulation (1995) 92:1479-86. doi:10.1161/01.CIR.92.6.1479

36. Mann DL. Inflammatory mediators and the failing heart: past, present, and the foreseeable future. Circ Res (2002) 91:988-98. doi:10.1161/01.RES.0000043825. $01705.1 \mathrm{~B}$

37. Moertl D, Hammer A, Steiner S, Hutuleac R, Vonbank K, Berger R. Dosedependent effects of omega-3-polyunsaturated fatty acids on systolic left ventricular function, endothelial function, and markers of inflammation in chronic heart failure of nonischemic origin: a double-blind, placebo-controlled, 3-arm study. Am Heart J (2011) 161(5):915.e1-9. doi:10.1016/j.ahj.2011.02.011

38. Baek D, Park Y. Association between erythrocyte n-3 polyunsaturated fatty acids and biomarkers of inflammation and oxidative stress in patients with and without depression. Prostaglandins Leukot Essent Fatty Acids (2013) 89(5):291-6. doi:10.1016/j.plefa.2013.09.008

39. Ramirez-Ramirez V, Macias-Islas MA, Ortiz GG, Pacheco-Moises F, TorresSanchez ED, Sorto-Gomez TE, et al. Efficacy of fish oil on serum of TNF $\alpha$, IL-1 $\beta$, and IL-6 oxidative stress markers in multiple sclerosis treated with interferon beta-1b. Oxid Med Cell Longev (2013) 2013:709493. doi:10.1155/2013/709493

40. Kar S, Webel R. Fish oil supplementation \& coronary artery disease: does it help? Mo Med (2012) 109:142-5.

41. Cysneiros RM, Arida RM, Terra VC, Sonoda EY, Cavalheiro EA, Scorza FA. To sushi or not to sushi: can people with epilepsy have sushi from time to time? Epilepsy Behav (2009) 16:565-6. doi:10.1016/j.yebeh.2009.08.019

42. Mozaffarian D, Wu JH. Omega-3 fatty acids and cardiovascular disease: effects on risk factors, molecular pathways, and clinical events. J Am Coll Cardiol (2011) 58:2047-67. doi:10.1016/j.jacc.2011.06.063

43. Domingo JL. Omega-3 fatty acids and the benefits of fish consumption: is all that glitters gold? Environ Int (2007) 33:993-8. doi:10.1016/j.envint.2007.05.001

44. Jeejeebhoy KN. Benefits and risks of a fish diet - should we be eating more or less? Nat Clin Pract Gastroenterol Hepatol (2008) 5:178-9. doi:10.1038/ ncpgasthep 1067

45. Natanson C, Eichenholz PW, Danner RL, Eichacker W, Hoffman D, Kuo SM, et al. Endotoxin and tumor necrosis factor challenges in dogs simulate the cardiovascular profile of human septic shock. J Exp Med (1989) 169:823-32. doi:10.1084/jem.169.3.823

Conflict of Interest Statement: The authors declare that the research was conducted in the absence of any commercial or financial relationships that could be construed as a potential conflict of interest.

Received: 11 October 2013; accepted: 13 November 2013; published online: 03 December 2013.

Citation: Scorza FA, Cavalheiro EA, Scorza CA, Galduróz JCF, Tufik S and Andersen ML (2013) Sleep apnea and inflammation - getting a good night's sleep with omega-3 supplementation. Front. Neurol. 4:193. doi: 10.3389/fneur.2013.00193 
This article was submitted to Sleep and Chronobiology, a section of the journal Frontiers in Neurology.

Copyright $\odot 2013$ Scorza, Cavalheiro, Scorza, Galduróz, Tufik and Andersen. This is an open-access article distributed under the terms of the Creative Commons Attribution
License (CC BY). The use, distribution or reproduction in other forums is permitted, provided the original author(s) or licensor are credited and that the original publication in this journal is cited, in accordance with accepted academic practice. No use, distribution or reproduction is permitted which does not comply with these terms. 